\title{
Antistatic and Thermal Properties of Poly(Lactic Acid)/ Polypropylene/Carbon Nanotube Nanocomposites
}

\author{
Wen Shyang Chow* and Yuan Ting Lim \\ School of Materials and Mineral Resources Engineering, Engineering Campus, \\ Universiti Sains Malaysia, 14300 Nibong Tebal, Pulau Pinang, Malaysia \\ "Corresponding author: shyang@usm.my
}

Published online: 10 December 2020

To cite this article: Wen Shyang Chow and Yuan Ting Lim (2020). Antistatic and thermal properties of poly(lactic acid)/polypropylene/carbon nanotube nanocomposites. Journal of Engineering Science, 16(2), 57-69, https://doi.org/10.21315/jes2020.16.2.3.

To link to this article: https://doi.org/10.21315/jes2020.16.2.3

\begin{abstract}
The aim of this study is to investigate the influence of carbon nanotubes (CNT) on the antistatic and thermal properties of poly(lactic acid)/polypropylene/carbon nanotubes (PLA/PP/CNT) nanocomposites. PLA/PP (blend ratio $=60: 40)$ containing CNT (loading 1.0 to $2.5 \mathrm{phr}$ ) was melt-compounded followed by compression moulding. The antistatic properties of PLA/PP/CNT nanocomposites achieved at $2.5 \mathrm{phr} C N T$ loading. Thermogravimetric analysis (TGA) results indicated that the thermal stability of PLA/PP/ CNT nanocomposite was higher than PLA/PP blend. Differential Scanning Calorimetry (DSC) results demonstrated that CNT reduced the cold crystallisation temperature of PLA, while increased the crystallisation temperature of $P P$, which evidenced the nucleatingability of CNT in the PLA/PP blends.
\end{abstract}

Keywords: antistatic, thermal properties, polymer blends, carbon nanotube, nanocomposites

\section{INTRODUCTION}

The use of a biopolymer could be a possible solution for the solid waste problem caused by the non-degradable polymeric materials, especially single-use plastics. Poly(lactic acid) (PLA) is a commercial available aliphatic polyester synthesised from renewable resources, e.g., sugarcane and corn starch. ${ }^{1-4}$ PLA exhibits good mechanical properties (high modulus and strength) and transparency. However, it shows low impact strength, low fracture toughness and slow crystallisation. . $^{5-7}$ Some strategies are applied to improve the properties of PLA, for example, polymer blending, copolymerisation, plasticisation, cross-linking and nanotechnology. ${ }^{8}$ 
Polymer blending is an economically viable and versatile industrial approach of modifying selected properties of the existing polymers. ${ }^{9} \mathrm{~A}$ thermoplastic blend is a common method used to produce PLA with desirable properties. Polypropylene (PP) offers outstanding chemical and moisture resistance, low density, good processability and relatively low cost. ${ }^{10,11}$ PLA is blended with PP to enhance toughness ${ }^{12}$ and dyeability. ${ }^{13}$

Polymer/conductive filler composite is potential material in antistatic packaging for electronic components. Electrostatic discharge (ESD) happens when there is a transfer of electric charges between bodies that have different electrostatic potentials. The effects of ESD on electronic components are often quite destructive. The product could experience complete failure and thus shorten the service life. Carbon nanotube (CNT) filled polymer composite is one of the feasible approaches to making antistatic packaging, for example, polyetherimide/ $\mathrm{CNT},{ }^{14}$ polystyrene/CNT ${ }^{15}$ and poly(trimethylene terephthalate)/CNT. ${ }^{16}$

Nanotechnology is a feasible method to modify the mechanical, thermal and electrical properties of PLA. ${ }^{17,18}$ Most of the research on PLA/CNT is focus on the enhancement in mechanical properties, crystallisation and electrical conductivity (mainly to make highly conductive PLA nanocomposites). ${ }^{19-21}$ Unfilled PLA has no conductive characteristic and always their ESD issue is a concern. The PLA/carbon black composite is less resistive than unfilled PLA and this makes the composite suitable for use as an antistatic packaging material for electronic components. ${ }^{22}$

PLA/PP blend is a possible packaging material for electronic components. The electrical properties of the PLA/PP blend are tunable by adding a suitable amount of CNT. CNT is selected attributed to electrical properties and crystallisation-ability. The novelty of this study is to obtain antistatic PLA/PP/ CNT nanocomposites with good thermal properties. Thus, the surface resistivity and thermal properties of the PLA/PP/CNT nanocomposite were investigated thoroughly.

\section{MATERIALS AND METHODS}

\subsection{Materials}

PLA (Ingeo ${ }^{\mathrm{TM}}$ 3251D) and PP (TitanPro) in pellets form were supplied by NatureWorks LLC (USA) and Lotte Chemical Titan (M) Sdn. Bhd., respectively. Multiwall carbon nanotubes (MWCNT) were purchased from Sun Nanotech Co. Ltd. The diameter and length of the MWCNT were in the range of $10 \mathrm{~nm}$ to $30 \mathrm{~nm}$ and $1 \mu \mathrm{m}$ to $10 \mu \mathrm{m}$, respectively. 


\subsection{Preparation of PLA/PP/CNT Nanocomposites}

The PLA and PP pellets were dehumidified in an oven at $60^{\circ} \mathrm{C}$ for $12 \mathrm{~h}$. PLA/ PP blends (60/40 wt \%) without and with CNT (loading: $1.0 \mathrm{phr}$ to $2.5 \mathrm{phr}$ ) were melt-compounded using an internal mixer (Haake Polydrive R600, Germany) at $170^{\circ} \mathrm{C}$ for $12 \mathrm{~min}$. The rotor speed was $60 \mathrm{rpm}$. The PLA/PP/CNT sheets (thickness $=1.5 \mathrm{~mm}$ ) were prepared using a compression molding machine at $170^{\circ} \mathrm{C}$. Table 1 shows the materials composition and designation of the PLA/PP/ CNT nanocomposites.

Table 1: Materials composition and designation of PLA/PP/CNT nanocomposites.

\begin{tabular}{lccc}
\hline Materials designation & PLA (wt \%) & PP (wt \%) & CNT (phr) \\
\hline PLA/PP (60/40) & 60 & 40 & - \\
PLA/PP/CNT (60/40/1.0) & 60 & 40 & 1.0 \\
PLA/PP/CNT (60/40/1.5) & 60 & 40 & 1.5 \\
PLA/PP/CNT (60/40/2.0) & 60 & 40 & 2.0 \\
PLA/PP/CNT (60/40/2.5) & 60 & 40 & 2.5 \\
\hline
\end{tabular}

\subsection{Sample Characterisation}

\subsubsection{Surface resistance test}

The surface resistivity of the samples was measured using a surface resistance meter. The test was carried out at room temperature. The sample geometry was $90 \mathrm{~mm} \times 60 \mathrm{~mm} \times 1.5 \mathrm{~mm}$ (length $\times$ width $\times$ thickness $)$.

\subsubsection{Thermogravimetric analysis (TGA)}

Thermal decomposition behaviour of the PLA/PP/CNT nanocomposites was determined using a thermogravimetric analyser (TGA) (Perkin Elmer, model Pyris 6, USA). The PLA/PP/CNT sample (specimen weight approximately $10 \mathrm{mg}$ ) was heated from $30^{\circ} \mathrm{C}$ to $600^{\circ} \mathrm{C}$ at a heating rate of $10^{\circ} \mathrm{C} \mathrm{min}{ }^{-1}$ under nitrogen gas atmosphere.

\subsubsection{Differential scanning calorimetry (DSC)}

DSC test was performed on PLA/PP/CNT nanocomposites using differential scanning calorimeter (Mettler Toledo, DSC 200, USA). The PLA/PP/CNT sample was scanned under an inert atmosphere of nitrogen gas from $30^{\circ} \mathrm{C}$ to $200^{\circ} \mathrm{C}$ with a heating and cooling rate of $10^{\circ} \mathrm{C} \mathrm{min}^{-1}$ for 2 cycles. The glass transition 
temperature $\left(T_{g}\right)$, melting temperature $\left(T_{m}\right)$, crystallisation temperature $\left(T_{c}\right)$ and cold-crystallisation temperature $\left(T_{c c}\right)$ of the PLA/PP samples were determined from the DSC second heating and cooling scan. The $T_{c c}$ is obtained from the exothermic peak in the DSC heating scan, while the $T_{c}$ was determined from the exothermic peak in the DSC cooling scan.

\section{RESULTS AND DISCUSSION}

\subsection{Antistatic Properties}

Table 2 shows the surface resistivity of PLA/PP blend and PLA/PP/CNT nanocomposites. The surface resistivity of insulator, antistatic, static dissipative and conductive materials are in the range of $10^{12}$ and above, $10^{10}$ to $10^{11}, 10^{5}$ to $10^{9}$ and $10^{1}$ to $10^{4} \Omega \mathrm{sq}^{-1}$, respectively. ${ }^{23}$ Pure PLA is electrically insulating with high surface resistivity (approximately $5 \times 10^{12} \Omega \mathrm{sq}^{-1}$ ). ${ }^{24}$ From Table 2 , it can be seen that the neat PLA, neat PP and PLA/PP/CNT (CNT loading: $1 \mathrm{phr}$ to $2 \mathrm{phr}$ ) with $>10^{12} \Omega \mathrm{sq}^{-1}$ surface resistivity are in the category of insulator materials. Interesting to note that the PLA/PP/CNT (60/40/2.5) nanocomposite is categorised as an antistatic material with surface resistivity of $1.90 \times 10^{11} \Omega \mathrm{sq}^{-1}$.

Table 2: Surface resistivity of PLA/PP/CNT nanocomposites.

\begin{tabular}{lcl}
\hline Materials designation & Surface resistivity $\left(\Omega \mathrm{sq}^{-1}\right)$ & Category \\
\hline PLA & $>10^{12}$ & Insulator \\
PP & $>10^{12}$ & Insulator \\
PLA/PP $(60 / 40)$ & $>10^{12}$ & Insulator \\
PLA/PP/CNT $(60 / 40 / 1.0)$ & $>10^{12}$ & Insulator \\
PLA/PP/CNT $(60 / 40 / 1.5)$ & $>10^{12}$ & Insulator \\
PLA/PP/CNT $(60 / 40 / 2.0)$ & $>10^{12}$ & Insulator \\
PLA/PP/CNT $(60 / 40 / 2.5)$ & $1.90 \times 10^{11}$ & Antistatic \\
\hline
\end{tabular}

Most of the research study aims to increase the conductivity of PLA or PP to make them become conductive materials. According to Luo et al., ${ }^{25}$ adding $5 \mathrm{wt} \%$ MWCNT into PLA forms a continuous conducting network and increase the electrical conductivity of PLA until $0.4 \mathrm{~S} \mathrm{~cm}^{-1}$. However, bear in mind that the main focus of this study is to develop PLA/PP/CNT nanocomposite with antistatic properties. It is believed that an antistatic property of PLA can be achieved at a lower loading of CNT. When CNT is sufficient to reduce their separation distance, some of the neighbouring CNT can electrically be connected and gave a conductive 
pathway network. However, when the CNT loading in the polymer matrix is below the percolation threshold, a large separation distance between the CNT might not alter their conductivity significantly. ${ }^{16}$ In this study, $2.5 \mathrm{phr}$ of CNT is sufficient to reduce the surface resistivity of PLA/PP blend and able to achieve antistatic behaviour for the nanocomposites. The better connectivity of the CNT gives a higher conductive pathway network in the PLA/PP matrix. The improvement in antistatic performances is associated to a well-constructed electrostatic discharge channel via CNT in the polymer matrix. ${ }^{15}$

\subsection{Thermogravimetric Analysis (TGA)}

Figures 1 and 2 show the TGA and DTG curves for PLA/PP/CNT nanocomposites. Table 3 shows the temperature at the onset decomposition $\left(T_{\text {onset }}\right)$, the decomposition temperature $\left(T_{d}\right)$ and the temperature at the maximum rate of decomposition ( $T_{\max }-$ recorded from the DTG). From Figure 1, it can be seen that the $T_{\text {onset }}$ of PP $\left(427.83^{\circ} \mathrm{C}\right)$ is higher than that of PLA $\left(332.88^{\circ} \mathrm{C}\right)$. In PLA/PP blend, PLA begins to degrade at $324.9^{\circ} \mathrm{C}$, whereas PP degrades at $402.0^{\circ} \mathrm{C}$. For PLA/PP/CNT nanocomposite, it is quite reasonable that the PLA would decompose first then followed by the PP.

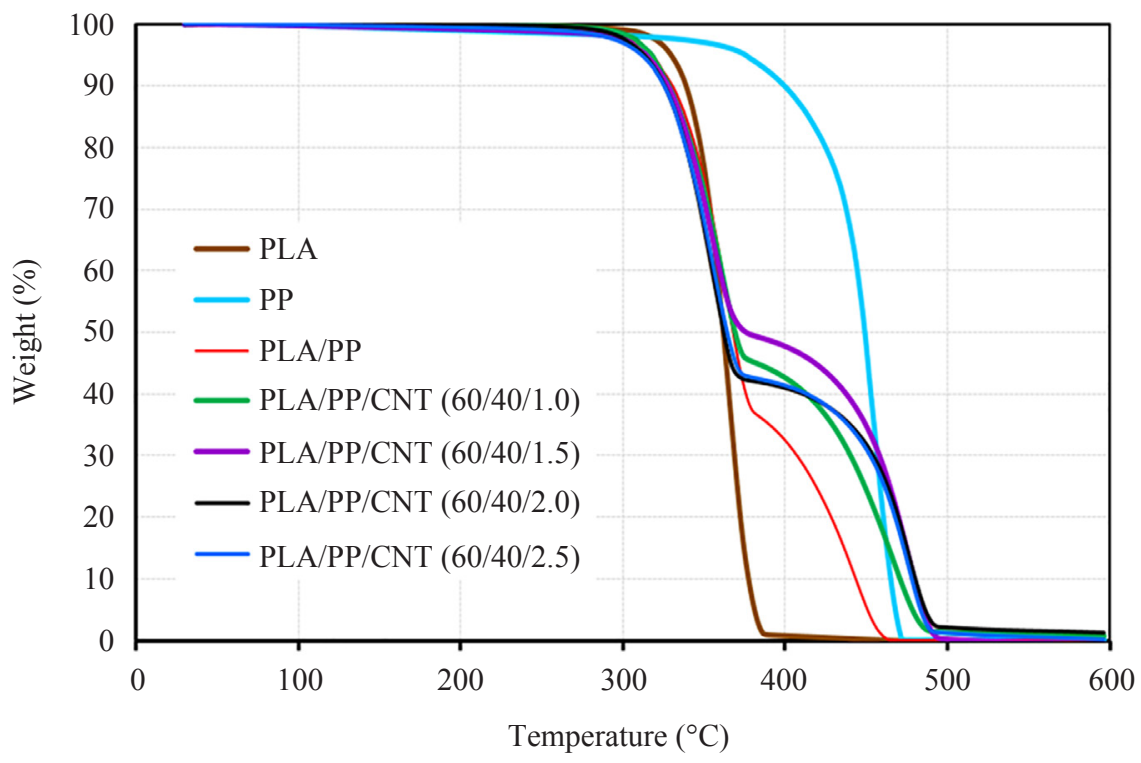

Figure 1: TGA curves of PLA/PP/CNT nanocomposites. 


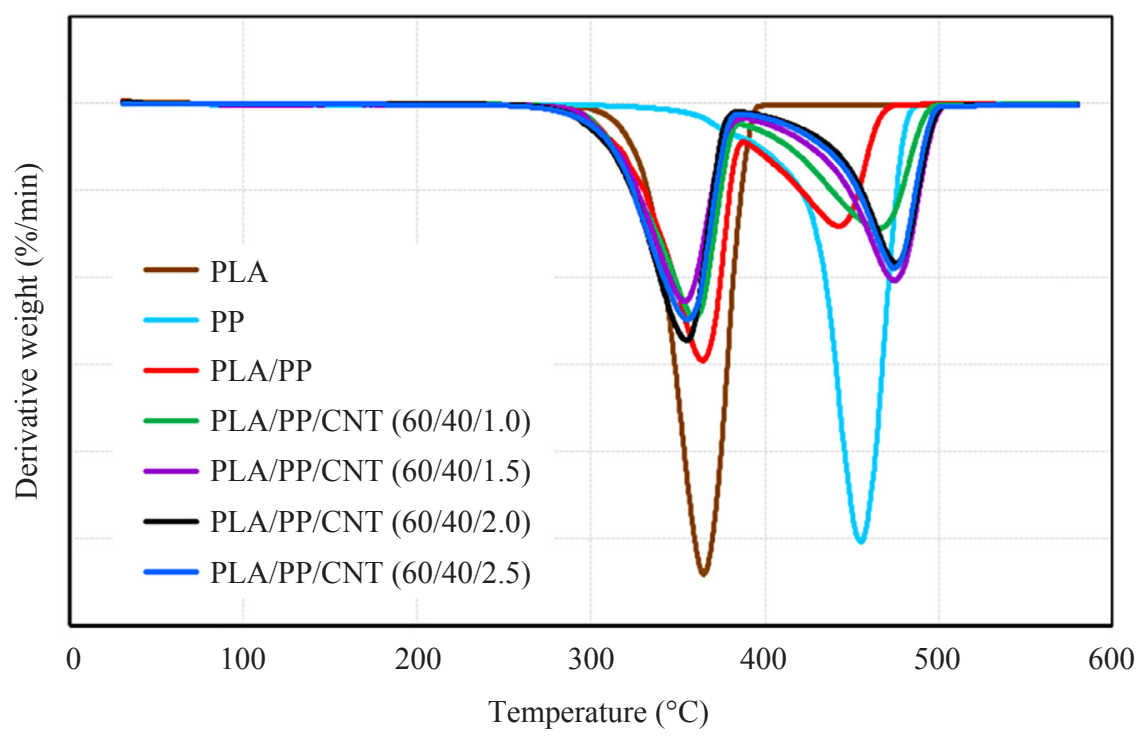

Figure 2: DTG curves of PLA/PP/CNT nanocomposites.

Table 3: TGA characteristics of PLA/PP blend and PLA/PP/CNT nanocomposites.

\begin{tabular}{|c|c|c|c|c|c|c|}
\hline \multirow[b]{2}{*}{ Materials designation } & \multicolumn{3}{|c|}{ PLA } & \multicolumn{3}{|c|}{$\mathrm{PP}$} \\
\hline & $\begin{array}{l}T_{\text {onset }} \\
\left({ }^{\circ} \mathrm{C}\right)\end{array}$ & $\begin{array}{l}T_{\max } \\
\left({ }^{\circ} \mathrm{C}\right)\end{array}$ & $\begin{array}{c}T_{d} \\
\left({ }^{\circ} \mathrm{C}\right)\end{array}$ & $\begin{array}{l}T_{\text {onset }} \\
\left({ }^{\circ} \mathrm{C}\right)\end{array}$ & $\begin{array}{l}T_{\max } \\
\left({ }^{\circ} \mathrm{C}\right)\end{array}$ & $\begin{array}{c}T_{d} \\
\left({ }^{\circ} \mathrm{C}\right)\end{array}$ \\
\hline Neat PLA & 332.88 & 364.74 & 388.26 & - & - & - \\
\hline Neat PP & - & - & - & 427.83 & 455.52 & 478.43 \\
\hline PLA/PP (60/40) & 324.97 & 363.38 & 383.92 & 402.01 & 443.00 & 466.46 \\
\hline PLA/PP/CNT (60/40/1.0) & 318.81 & 359.61 & 379.85 & 407.28 & 465.89 & 491.30 \\
\hline PLA/PP/CNT (60/40/1.5) & 325.86 & 360.14 & 380.01 & 430.62 & 471.47 & 494.13 \\
\hline PLA/PP/CNT (60/40/2.0) & 313.63 & 354.93 & 375.86 & 439.74 & 475.72 & 496.71 \\
\hline PLA/PP/CNT (60/40/2.5) & 310.35 & 355.09 & 377.86 & 438.29 & 474.48 & 494.97 \\
\hline
\end{tabular}

According to Salam and Burk, ${ }^{26}$ the TGA results showed that the weight loss of pristine MWCNT (same grade as in this study) was approximately $2 \mathrm{wt} \%$ at $800^{\circ} \mathrm{C}$. This indicates that the CNT is highly thermal stable. However, in the open literature, it was reported that adding CNTs could increase or decrease the thermal properties of polymers, depending on various conditions, e.g., the types of polymers, loading of CNTs, surface modifications of CNTs and TGA testing conditions. ${ }^{27}$ From Table 3, one can observe that the effect of CNT on the PLA and PP is different. The $T_{\text {onset, }} T_{\max }$ and $T_{d}$ of the PLA phase in the PLA/PP/CNT 
are slightly lower or comparable to the PLA phase in the PLA/PP blend. This is maybe associated with the fact that the CNT exhibits high thermal conductivity and assists in heat dissipation in polymer nanocomposites. This subsequently reduces the decomposition activation energy and thermal degradation occurs at a lower temperature. ${ }^{28}$ Another possible reason is that the PLA is sensitive to thermal degradation and prone to decomposition during the high heat dissipation of the CNT. Interesting to note that the $T_{\text {onset }}, T_{\max }$ and $T_{d}$ of the PP phase in the $\mathrm{PLA} / \mathrm{PP} / \mathrm{CNT}$ are higher than the PP phase in the PLA/PP blend. This indicates that the CNT could delay the thermal decomposition of PP in the PLA/PP nanocomposites. Thus, based on the overall performance, the CNT can increase the thermal stability of the PLA/PP blends. A similar finding was reported by Satish et al. ${ }^{29}$ in which the maximum thermal degradation temperature of polymer was enhanced by the incorporation of CNT.

\subsection{DSC}

Figures 3 and 4 show the DSC of heating and cooling curves of PLA/PP/CNT nanocomposites. Table 4 summarises the DSC characteristics of the PLA/PP nanocomposites. The melting temperature $\left(T_{m}\right)$ of neat PLA and PP is quite close, i.e., $167.1^{\circ} \mathrm{C}$ and $165.8^{\circ} \mathrm{C}$, respectively. It is reasonable that the PLA/PP and PLA/ $\mathrm{PP} / \mathrm{CNT}$ only exhibits one $T_{m}$, due to the possible overlapping of the endothermic peaks. The $T_{g}$ and $T_{m}$ of PLA/PP/CNT are comparable to that of the PLA/PP blend. This indicates that the CNT did not influence much on the $T_{g}$ and $T_{m}$ of the blends. Note that the cold crystallisation temperature $\left(T_{c c}\right)$ of PLA $\left(136.3^{\circ} \mathrm{C}\right)$ was shifted to a lower temperature $\left(T_{c c}=95^{\circ} \mathrm{C}\right.$ to $\left.97^{\circ} \mathrm{C}\right)$ by adding of the CNT. This is due to the nucleating effect of the CNT, which can facilitate the crystal packing simultaneously in the PLA phase. Higher loading of nanofiller in the polymer system indicates a higher proportion of nucleating agent that promotes more crystallisation nuclei and thus increasing the crystallisation of the polymer. 


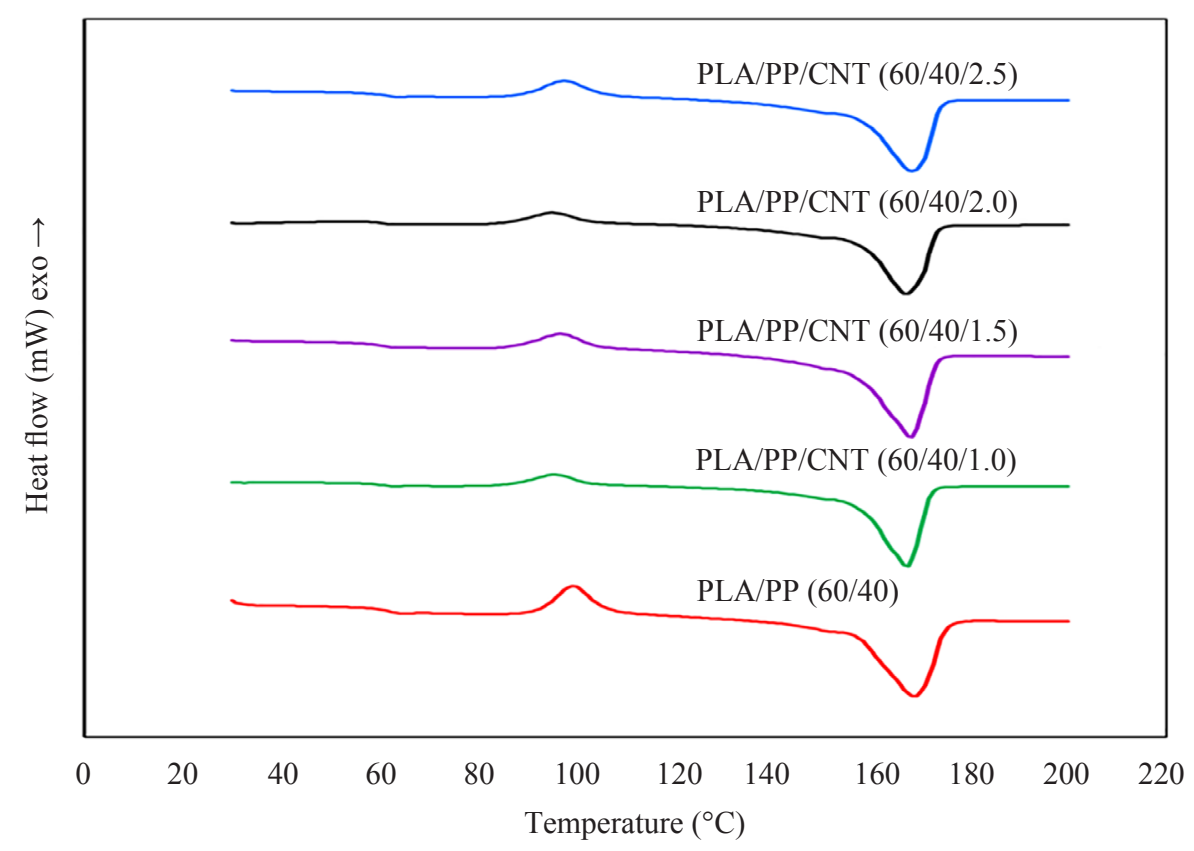

Figure 3: DSC heating curves of PLA/PP/CNT nanocomposites.

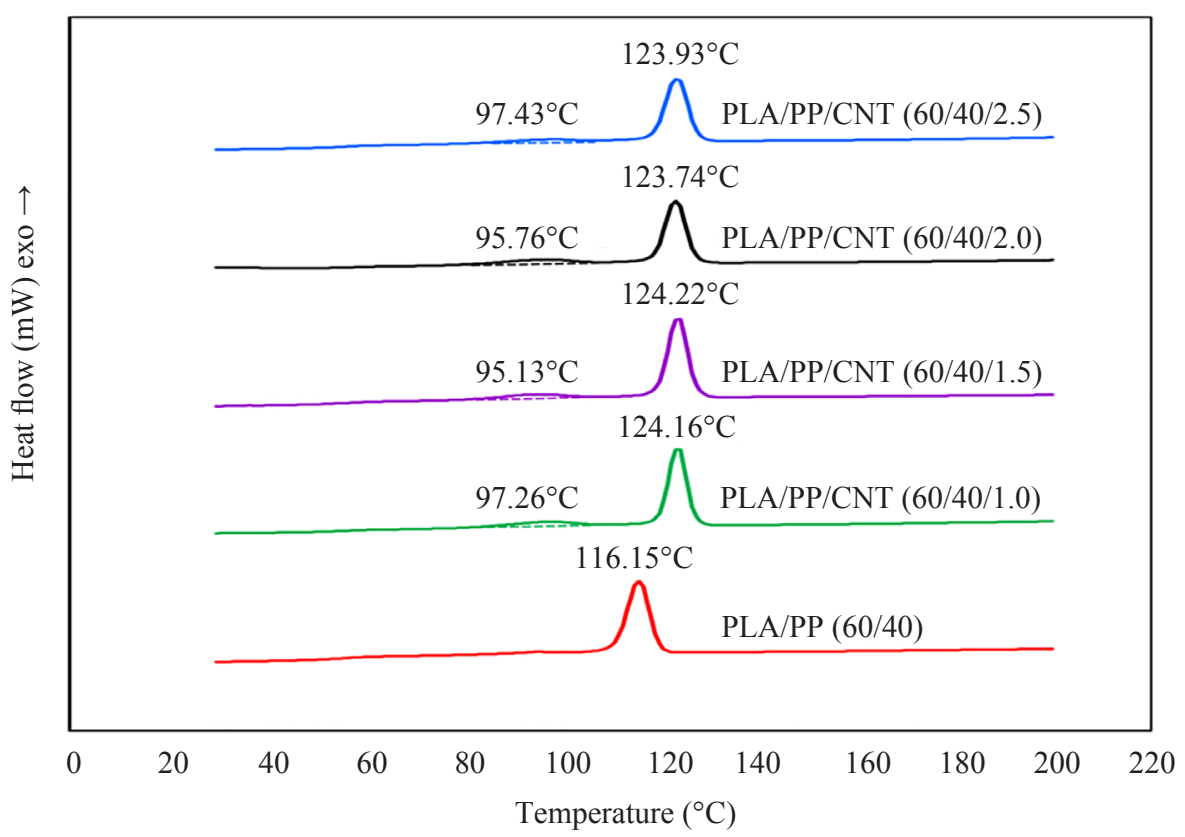

Figure 4: DSC cooling curves of PLA/PP/CNT nanocomposites. 
Table 4: DSC characteristics of neat PLA, neat PP, PLA/PP blend and PLA/PP/CNT nanocomposites.

\begin{tabular}{lccccc}
\hline Materials designation & $T_{g}\left({ }^{\circ} \mathrm{C}\right)$ & $T_{m}\left({ }^{\circ} \mathrm{C}\right)$ & $T_{c c(\mathrm{PLA})}\left({ }^{\circ} \mathrm{C}\right)$ & $T_{c 1(\mathrm{PP})}\left({ }^{\circ} \mathrm{C}\right)$ & $T_{c 2(\mathrm{PP})}\left({ }^{\circ} \mathrm{C}\right)$ \\
\hline PLA & 60.63 & 167.14 & 136.29 & - & - \\
PP & - & 165.82 & - & - & 128.75 \\
PLA/PP (60/40) & 61.84 & 168.23 & 99.15 & - & 116.15 \\
PLA/PP/CNT (60/40/1.0) & 59.77 & 166.97 & 95.49 & 97.26 & 124.16 \\
PLA/PP/CNT (60/40/1.5) & 60.84 & 167.53 & 96.78 & 95.13 & 124.22 \\
PLA/PP/CNT (60/40/2.0) & 60.73 & 166.83 & 95.14 & 95.76 & 123.74 \\
PLA/PP/CNT (60/40/2.5) & 60.35 & 167.97 & 97.48 & 97.43 & 123.93 \\
\hline
\end{tabular}

From Figure 4, the PLA/PP blend only exhibits one $T_{c}$ at about $116^{\circ} \mathrm{C}$. However, an obvious $T_{c}\left(123.7^{\circ} \mathrm{C}\right.$ to $\left.124.2^{\circ} \mathrm{C}\right)$ and a broad shoulder exothermic peak $\left(95^{\circ} \mathrm{C}\right.$ to $\left.97^{\circ} \mathrm{C}\right)$ are detected in the PLA/PP/CNT nanocomposites. This is due to the formation of the imperfect crystals in PP by adding CNT. ${ }^{30,31}$ Nevertheless, the amount of the imperfect crystals is rather insignificant as the exothermic peak $\left(T_{c 1}\right)$ is quite small. Furthermore, it can be seen that the crystallisation temperature of PLA/PP/CNT $\left(124^{\circ} \mathrm{C}\right)$ is relatively higher than that of PLA/PP $\left(T_{c}=116^{\circ} \mathrm{C}\right)$. The increase in $T_{c}$ is associated with the nucleating- and crystallisation-ability of the CNT. It is known that an appropriate amount of CNT can induce crystallisation of semi-crystalline polymer at higher temperatures by reducing the nucleation activation energy and increasing the nucleation density. This will lead to the acceleration of crystallisation for the polymer/CNT nanocomposites. ${ }^{32,33}$

\section{CONCLUSION}

In this study, it is proven that antistatic material can be prepared by incorporating $\mathrm{CNT}$ into the PLA/PP blend. The PLA/PP/CNT nanocomposite achieved antistatic properties at $2.5 \mathrm{phr}$ of CNT loadings. Although CNT demonstrated different effects on the thermal decomposition on PLA and PP (i.e., promotes the thermal decomposition of PLA, while delays the thermal degradation of PP), the overall thermal stability of PLA/PP/CNT nanocomposites is higher than that of PLA/PP blends. DSC results show that the CNT decreased the $T_{c c}$ of PLA, while increased the $T_{c}$ of PP. This suggests that the CNT can act as a nucleating agent for the PLA/PP nanocomposite, which can then improve their productivity during manufacturing. 


\section{ACKNOWLEDGEMENTS}

The authors would like to express their appreciation to Universiti Sains Malaysia for Research University Grant (1001/PBAHAN/8014024).

\section{REFERENCES}

1. Imre, B., Renner, K. \& Pukánszky, B. (2014). Interactions, structure and properties in poly(lactic acid)/thermoplastic polymer blends. Express Polym. Lett., 8(1), 2-14, https://doi.org/10.3144/expresspolymlett.2014.2.

2. Hamad, K., Kaseem, M., Yang, H. W., Deri, F. \& Ko, Y. G. (2015). Properties and medical applications of polylactic acid: A review. Express Polym. Lett., 9(5), 435-455, https://doi.org/10.3144/expresspolymlett .2015.42.

3. Chow, W. S., Teoh, E. L. \& Karger-Kocsis, J. (2018). Flame retarded poly(lactic acid): A review. Express Polym. Lett., 12(5), 396-417, https://doi.org/10.3144/expresspolymlett.2018.34.

4. Gan, I. \& Chow, W. S. (2019). Synthesis of phosphoric acidtreated sugarcane bagasse cellulose nanocrystal and its thermal properties enhancement for poly(lactic acid) nanocomposites. J. Thermoplast. Compos. Mater., 32(5), 619-634, https://doi.org/10.1177/ 0892705718772866.

5. Ahmed, J. \& Varshney, S. K. (2011). Polylactides: Chemistry, properties and green packaging technology: A review. Int. J. Food Prop., 14(1), 37-58, https://doi.org/10.1080/10942910903125284.

6. Imre, B. \& Pukánszky, B. (2013). Compatibilization in bio-based and biodegradable polymer blends. Eur. Polym. J., 49(6), 1215-1233, https://doi.org/10.1016/j.eurpolymj.2013.01.019.

7. Song, Z. P., Xiao, H. N. \& Zhao, Y. (2014). Hydrophobic-modified nanocellulose fiber/PLA biodegradable composites for lowering water vapor transmission rate (WVTR) of paper. Carbohydr. Polym., 111, 442-448, https://doi.org/10.1016/j.carbpol.2014.04.049.

8. Chow, W. S. \& Lok, S. K. (2009). Thermal properties of poly(lactic acid)/organo-montmorillonite nanocomposites. J. Therm. Anal. Calorim., 95(2), 627-632, https://doi.org/10.1007/s10973-007-8975-x.

9. Chow, W. S. (2019). Polypropylene blends: properties control by design. In J. Karger-Kocsis \& T. Bárány (eds.), Polypropylene handbook: Morphology, blends and composites. New York: Springer, 419-480, https://doi.org/10.1007/978-3-030-12903-3_8. 
10. Sommai, P., Jutamas, K., Weraporn, P., Rutchaneekorn, W., Narongchai, O., Sorapong, P. et al. (2016). Effect of compatibilizer on PLA/PP blend for injection molding. Energy Procedia, 89, 353-360, https://doi. org/10.1016/j.egypro.2016.05.046.

11. Sui, G., Jing, M., Zhao, J., Wang, K. Zhang, Q. \& Fu, Q. (2018). A comparison study of high shear force and compatibilizer on the phase morphologies and properties of polypropylene/polylactide (PP/PLA) blends. Polymer, 154, 119-127, https://doi.org/10.1016/ j.polymer.2018.09.005.

12. Hamad, K., Kaseem, M. \& Deri, F. (2011). Rheological and mechanical characterization of poly(lactic acid)/polypropylene polymer blends. J. Polym. Res., 18, 1799-1806, https://doi.org/10.1007/s10965-011 -9586-6.

13. Reddy, N., Nama, D. \& Yang, Y. (2008). Polylactic acid/polypropylene polyblend fibers for better resistance to degradation. Polym. Degrad. Stab., 93, 233-241, https://doi.org/10.1016/j.polymdegradstab.2007 .09 .005 .

14. Li, K., Zhang, C., Du, Z. J., Li, H. Q. \& Zou, W. (2012). Preparation of humidity-responsive antistatic carbon nanotube/PEI nanocomposites. Synth. Met., 162, 2010-2015, https://doi.org/10.1016/ j.synthmet.2012.09.014.

15. Zhang, M., Zhang, C., Du, Z. J., Li, H. Q. \& Zou, W. (2017). Preparation of antistatic polystyrene superfine powder with polystyrene modified carbon nanotubes as antistatic agent. Compos. Sci. Technol., 138, 1-7, https://doi.org/10.1016/j.compscitech.2016.11.010.

16. Braga, N. F., Zaggo, H. M., Montagna, L. S. \& Passador, F. R. (2020). Effect of carbon nanotubes (CNT) functionalization and maleic anhydride-grafted poly(trimethylene terephthalate) (PTT-g-MA) on the preparation of antistatic packages of PTT/CNT nanocomposites. J. Compos. Sci., 4, 1-18, https://doi.org/10.3390/jcs4020044.

17. Díez-Pascual, A. M., Naffakh, M., Marco, C., Gómez-Fatou, M. A. \& Ellis, G. J. (2014). Multiscale fiber-reinforced thermoplastic composites incorporating carbon nanotubes: A review. Curr. Opin. Solid State Mater. Sci., 18, 62-80, https://doi.org/10.1016/j.cossms.2013.06.003.

18. Linè, C., Larue, C. \& Flahaut, E. (2017). Carbon nanotubes: Impacts and behaviour in the terrestrial ecosystem; A review. Carbon, 123, 767-785, https://doi.org/10.1016/j.carbon.2017.07.089. 
19. Kuan, C. F., Chen, C. H., Kuan, H. C., Lin, K. C., Chiang, C. L. \& Peng, H. C. (2008). Multi-walled carbon nanotube reinforced poly(Llactic acid) nanocomposites enhanced by water-crosslinking reaction. J. Phys. Chem. Solids, 69, 1399-1402, https://doi.org/10.1016/ j.jpcs.2007.10.061.

20. Ramontja, J., Ray, S. S., Pillai, S. K. \& Luyt, A. S. (2009). High performance carbon nanotube-reinforced bioplastic. Macromol. Mater. Eng., 294, 839-846, https://doi.org/10.1002/mame.200900197.

21. Mora, A., Verma, P. \& Kumar, S. (2020). Electrical conductivity of CNT/polymer composites: 3D printing, measurements and modeling. Compos. Part B., 183, 107600/1-107600/11, https://doi.org/10.1016/ j.compositesb.2019.107600.

22. Silva, T. F., Menezes, F., Montagna, L. S., Lemes, A. P. \& Passador, F. R. (2019). Preparation and characterization of antistatic packaging for electronic components based on poly(lactic acid)/carbon black composites. J. Appl. Polym. Sci., 136(13), 47273, https://doi.org/10.1002/ app.47273.

23. Bhattacharya, S. S. \& Amin, H. N. (2015). Analysis of surface resistivity behavior of conductive woven fabrics made from copper jari \& S.S./ polyester yarns for ESD control. Int. Res. J. Eng. Technol., 2(9), 10071012.

24. Gonçalves, C., Gonçalves, I. C., Magalhães, F. D. \& Pinto, A. M. (2017). Poly(lactic acid) composites containing carbon-based nanomaterials: A review. Polymers, 9(7), 269/1-269/37, https://doi.org/10.3390/ polym9070269.

25. Luo, J. J., Wang, H. B., Zuo, D. Q., Ji, A. P. \& Liu, Y. W. (2018). Research on the application of MWCNTs/PLA composite material in the manufacturing of conductive composite products in 3D printing. Micromachines, 9(12), 635/1-635/13, https://doi.org/10.3390/mi9120635.

26. Salam, M. A. \& Burk, R. (2017). Synthesis and characterization of multiwalled carbon nanotubes modified with octadecylamine and polyethylene glycol. Arab. J. Chem., 10, S921-S927.

27. Winey, K. I., Kashiwagi, T. \& Mu, M. (2007). Improving electrical conductivity and thermal properties of polymers by the addition of carbon nanotubes as fillers. MRS Bull., 32(4), 348-353, https://doi.org/10 $.1557 / \mathrm{mrs} 2007.234$.

28. Ciecierska, E., Boczkowska, A., Kurzydlowski, K. J., Rosca, I. D. \& Hoa, S. V. (2013). The effect of carbon nanotubes on epoxy matrix nanocomposites. J. Therm. Anal. Calorim., 111, 1019-1024, https://doi.org/10.1007/s10973-012-2506-0. 
29. Satish, G., Prasad, V. V. S. \& Ramji, K. (2017). Manufacturing and characterization of CNT based polymer composites. Math. Models Eng., 3(2), 89-97, https://doi.org/10.21595/mme.2017.19121.

30. Omonov, T. S., Harrats, C., Moldenaers, P. \& Groeninck, G. (2007). Phase continuity detection and phase inversion phenomena in immiscible polypropylene/polystyrene blends with different viscosity ratios. Polymer, 48(20), 5917-5927, https://doi.org/10.1016/j.polymer .2007.08.012.

31. Santana, O. O. \& Müller, A. J. (1994). Homogeneous nucleation of the dispersed crystallisable component of immiscible polymer blends. Polym. Bull., 32, 471-477, https://doi.org/10.1007/BF00587890.

32. Li, L., Li, C. Y., Ni, C., Rong, L. \& Hsiao, B. (2007). Structure and crystallization behavior of nylon 66/multi-walled carbon nanotube nanocomposites at low carbon nanotube contents. Polymer, 48(12), 3452-3460, https://doi.org/10.1016/j.polymer.2007.04.030.

33. Kim, J. Y., Park, H. S. \& Kim, S. H. (2006). Unique nucleation of multi-walled carbon nanotube and poly(ethylene 2,6-naphthalate) nanocomposites during non-isothermal crystallization. Polymer, 47(4), 1379-1389, https://doi.org/10.1016/j.polymer.2005.12.042. 